\title{
The Quality of Leader-Member Exchange (LMX): A Multilevel Analysis of Individual-level, Organizational-level and Societal-level Antecedents
}

\author{
${ }^{\mathrm{a}}$ Monash University, Malaysia \\ ${ }^{\mathrm{b}}$ University Fellows International Research Consortium, USA \\ ${ }^{\mathrm{c}}$ Florida Atlantic University, USA \\ ${ }^{\mathrm{d}}$ University of Hartford, USA \\ e Instituto Tecnológico de Celaya, Mexico \\ ${ }^{\mathrm{f}}$ Université de Fribourg, Switzerland \\ ${ }^{\mathrm{g}}$ Chinese Academy of Sciences, China \\ ${ }^{\mathrm{h}}$ University of Valencia, Spain
}

Jane Terpstra-Tong ${ }^{\mathrm{a}, *}$, David A. Ralston ${ }^{\mathrm{b}}$, Len J. Treviño ${ }^{\mathrm{c}}$, Irina Naoumova ${ }^{\mathrm{d}}$, María Teresa de la Garza Carranza ${ }^{\mathrm{e}}$, Olivier Furrer ${ }^{\mathrm{f}}$, Yongjuan $\mathrm{Li}^{\mathrm{g}}{ }^{\mathrm{g}}$, Fidel León Darder ${ }^{\mathrm{h}}$

\section{A R T I C L E I N F O}

\section{Keywords:}

LMX

Societal culture

Organizational culture

Individual values

Multilevel analysis

\begin{abstract}
A B S T R A C T
We examine the direct relationships for both individual values and organizational-level culture on the quality of leader-member exchange (LMX) in a multilevel, multi-society study. In addition, we investigate the moderating roles of organizational- and societal-level cultures. Using 2343 respondents from 12 samples, we performed hierarchical linear modelling analysis and found that individual-level collectivism and organizational-level clan and hierarchy cultures were positively related to LMX, while individual-level individualism and organizational-level market and adhocracy cultures were negatively related to LMX. None of the organizational culture types or societal cultures had any moderating effects. One implication of the lack of moderating findings is that the main effect findings may be global, suggesting that they are not constrained by the organizational culture or societal culture in which they are embedded. We discuss additional implications for these findings.
\end{abstract}

\section{Introduction}

Leader-member exchange (LMX) is a relational approach to leadership (Anand et al., 2011; Bauer and Erdogan, 2015) that examines the dyadic relationship between subordinates (members) and their immediate supervisors (leader). Previous LMX studies that focused on a single country found that leaders form differentiated relationships with each subordinate and incorporate them into either ingroups or outgroups (Scandura and Graen, 1984; Graen and Uhl-Bien, 1995). Ingroup members tend to develop high LMX quality, characterized by high mutual trust, respect and reciprocity, while outgroup members do not. In addition, high LMX quality has been found to be associated with higher member task performance (Dansereau et al., 1975; Gerstner and Day, 1997; Bauer et al.,

\footnotetext{
* Corresponding author.

E-mail addresses: jane.tong@monash.edu (J. Terpstra-Tong), dralston@ou.edu (D.A. Ralston), trevinol@fau.edu (L.J. Treviño), naoumova@hartford.edu (I. Naoumova), tgarza@itc.mx (M.T. de la Garza Carranza), olivier.furrer@unifr.ch (O. Furrer), liyj@psych.ac.cn (Y. Li), fidel.leon@uv.es (F.L. Darder).
} 
2006), extra-role behaviors (Uhl-Bien and Maslyn, 2003; Ilies et al., 2007), job satisfaction (Erdogan and Enders, 2007; Harris et al., 2009), commitment (Eisenberger et al., 2010; Liden et al., 2000), creativity (Atwater and Carmeli, 2009; Liao et al., 2010), and lowered intention to leave (Bauer et al., 2006; Harris et al. 2009). Despite the positive LMX impact on work outcomes, the antecedents of LMX in international research are still under-researched, with only a few studies having adopted a cross-cultural approach (Nahrgang and Seo, 2015; Rockstuhl et al., 2012).

Surprisingly, the impact of values-the driver of individuals' behavior (Markus and Kitayama, 1991; Rokeach, 1973) and a core distinguisher of interdependence (group-oriented) versus independence (self-oriented) cultures (Schwartz, 1992)—on LMX quality has not been explored. This is unfortunate because, as the workplace continues to become more global (Tung, 2008), understanding phenomenon, such as LMX, becomes increasingly important for businesses to function effectively. Hence, we concur with Pellegrini (2015) that to advance LMX theory, studying LMX through the international lens should be a priority.

\subsection{Predictors of $L M X$}

Among the antecedents of LMX that have been studied, leader variables were found to be crucial in the LMX relationships (Dulebohn et al., 2012). Because of the inherent power differential in the leader-member relationship, leaders generally have more control in the relationship and hence shape members' perceptions and responses to them (Graen and Uhl-Bien, 1995; Nahrgang et al., 2009). Specifically, through various leadership processes, leader contingent reward behaviors (Liden et al., 1997), leader expectations of follower success (Liden et al., 1993), transformational leadership (Anand et al., 2011), extraversion (Bauer et al., 2006) and agreeableness (Erdogan and Liden, 2002) have a positive impact on LMX quality. Abusive leadership, on the other hand, has a negative impact on LMX quality (Xu et al., 2012). Another group of antecedents of LMX quality is related to the interpersonal relationship variables that are essential in fostering mutual bonding. Those variables serve as the stimuli that positively affect the leader's or member's perception of each other and thereby enhance LMX quality. Because indivduals tend to develop attraction with people who are similar to them and whom they like, variables such as members' perceptions of similarity or congruence (Liden et al., 1993), leader trust (Liden and Maslyn, 1998), affect or liking (Wayne and Ferris, 1990) were found positively related to LMX quality.

As work relationships involve continuous interplay between partners, and reciprocity is a two-way process (Ferris et al., 2019), we contend that members (subordinates) also have significant influence in the dyadic LMX relationship (Maslyn and Uhl-Bien, 2001). We argue that developing a greater understanding of the impact of subordinate attributes on LMX quality, apart from the well-studied follower variables (competence, effort, Big-five personality traits, positive and negative affectivity and locus of control) (Dulebohn et al., 2012), will likely bring new insights to LMX development research. These insights could further our understanding of violation of LMX relationship and relationship repair, two-related areas that await more research attention (Nahrgang and Seo, 2015).

One characteristic of members that could serve as a predictor of the LMX relationship is their fundamental values, in particular, individual-level collectivism and individualism. Values are a core individual distinction that shapes individuals' cognition, emotion and motivation (Markus and Kitayama, 1991; Schwartz, 1992). One's collectivistic vis-à-vis individualistic orientation affects how one perceives and feels the need of attending to others, fitting in, and achieving harmonious interdependence with others (Kwan et al., 1997). In short, values affect individuals' psychological need to be, or not to be, part of a group (ingroup).

As individuals' behavior is nested within three levels of values/cultures - micro (individual- level), meso (organizational-level) and macro (societal-level) (Vora et al., 2018), the question that we investigate in this study is: to what degree, if any, do the values/ cultures of each of these three levels have on the leader-member relationship? Specifically, we have two overarching goals: (1) to investigate main effects on LMX at the individual and organizational levels in the cross-cultural context; and (2) to investigate possible organizational- and/or societal-level moderating effects on the LMX relationship in the cross-cultural context. Neither of these goals has been investigated previously and certainly not simultaneously. To this end, we aim to investigate the way and the extent to which individual values, embedded in organizational-level culture and societal-level culture, impact LMX quality. Thus, our study will extend our understanding of member characteristics on LMX quality and add to the international LMX research, a field that is still under-explored and in need of substantially more in-depth research (Pellegrini, 2015; Rockstuhl et al., 2012; Selvarajan et al., 2018).

\subsection{Study objectives}

We have developed four specific objectives to attain the overarching goals we previously articulated. By applying a multilevel modelling design, we first examine if there are main effects of individual-level values on LMX quality. Second, we examine if there are main effects of organizational-level cultures on LMX quality. Third, we assess the extent to which meso-level organizational cultures moderate the relationship between individual-level values and LMX. Finally, we test for a cross-level moderating effect of societallevel culture on the relationship between individual-level values and LMX. Our findings will assist in clarifying how individuals' values, nested within organizational culture and societal culture, impact a relationship-based leadership phenomenon, LMX. To do so, we will use collectivism and individualism as measures of culture at the individual and the societal levels. These two dimensions are the most commonly used values dimensions in cross-cultural studies, and they, as we postulate in Section 2.2, are relevant to explain how members view and approach their relationship with their supervisors.

In the following sections of the paper, we begin by presenting the theoretical foundation of this study. We then present the hypothesized main effects between the micro-level individual values, the meso-level organizational culture and LMX, separately. We follow this with a discussion of how organizational- and societal-level cultures might moderate the individual values-LMX relationship. We then describe our methods and report our results. In turn, we discuss our findings including their practical 
implications. We conclude by identifying the study limitations and possible directions for future research.

\section{Theoretical background and hypothesis development}

\subsection{Theoretical foundation}

As we have noted, limited research has been devoted to examining LMX in the international or cross-cultural context. Accordingly, there is a substantial and growing need for the development of theoretical reasoning surrounding this context. Because our investigation of LMX integrates the impact of micro-level values, meso-level culture and macro-level culture, it is necessary to develop a multi-level theoretical foundation, which incorporates the impact of relevant variables at each of the three levels.

To this end, we begin to develop our theoretical foundation with the theory of ingroup-outgroup relationships (Brewer and Chen, 2007; Triandis, 1995), which was synonymous with early LMX research (Dansereau et al., 1975; Scandura and Graen, 1984; Scandura, 1999). Ingroup member relationships may be described as those where members tend to feel obligated to devote their loyalty to other group members. Ingroup members tend to develop obligatory interdependence with, exercise depersonalized trust with and hold positive regard towards other ingroup members. Typical ingroup relationships are also characterized by ingroup pride and identification and indiscriminate cooperation. In decision making, ingroups give preference to their members and to some extent it could be viewed as ingroup favoritism (Balliet et al., 2014). All these ingroup behaviors are primarily based upon ingroup membership. Conversely, outgroup member relationships may be described as calculative and exploitative, and often imply a social distance. Outgroup members, as opposed to ingroup members, are more often associated with negativity, hostility, threat and fear (Brewer, 1999; Triandis, 1995).

Aligned with the ingroup-outgroup theory, LMX theory holds that leaders form differentiated relationships with each subordinate and incorporate them into ingroups or outgroups (Scandura and Graen, 1984; Graen and Uhl-Bien, 1995). LMX with ingroup members follows social exchange principles that involves unspecified obligations and continuous reciprocity (Gouldner, 1960; Liden et al., 1997). On the contrary, LMX with outgroup members tends to be economic-based and transactional involving limited negotiating latitude and balanced reciprocity (Graen and Uhl-Bien, 1995). Thus, LMX relationships may be viewed as a continuum, with one end referring to ingroup relationship (high quality LMX) and the other end referring to outgroup relationship (low quality LMX). The question then becomes what drives the level of ingroup-outgroup relationship, which in turn determines the quality of LMX? The answer is the impact of the micro, meso and macro environment upon the ingroup-outgroup relationship. Thus, we integrate three unique, but related sets of theories to incorporate the impact of the various levels of the environment into our model.

We represent the micro-level by theories of cross-cultural values (Brewer and Chen, 2007; Markus and Kitayama, 1991; Triandis, 1995). And, to theorize the main effects of the micro-level relationship of values and LMX, we utilize the collectivism and individualism values constructs, since ingroup-outgroup relationship theory is situated at the core of the collectivism and individualism constructs. Importantly, multiple frameworks of values, such as Kluckhohn and Strodtbeck (1961), Hofstede (1980), Triandis et al. (1986), Schwartz (1992), Trompenaars (1994), Inglehart (1997), House et al. (2004), and Ralston et al. (2018), have repeatedly found these two constructs to be central to understanding human values. Further, these constructs manifest at both the individual and the societal levels, although at the individual level these constructs are also labelled as independent versus interdependent selfconstruals (Markus and Kitayama, 1991) or idiocentrism versus allocentrism (Triandis, 1995). Crucial to our study, ingroup-outgroup theory states that collectivism, rather than individualism, is associated with ingroup orientation (Brewer and Chen, 2007).

We represent the meso-level by theories of organizational culture, with foci on schemata and social control (Bartunek and Moch, 1987; O'Reilly and Chatman, 1996). Thus, to theorize the meso-level main effects, we use the Competing Values Framework (CVF) (Cameron and Ettington, 1988; Cameron and Quinn, 1999) to understand organizational culture. This popular framework differentiates organizational culture along two continua. The first continuum has flexibility and dynamism on the one end and stability and control on the other. The second continuum consists of internal orientation and integration on one end and external orientation and differentiation on the other. These two continua form a circumplex model with four distinct organizational cultural types - clan, which emphasizes flexibility and integration; adhocracy, which emphasizes flexibility and differentiation; market, which emphasizes control and differentiation; and hierarchy, which emphasizes control and integration.

We represent the macro-level by theories of person-environment (PE) fit/misfit (Kristof-Brown et al., 2005; Kristof-Brown and Guay, 2011), and in particular, one of its derivatives, trait-activation theory (Tett and Burnett, 2003). To theorize the moderating roles of organizational culture and societal culture, PE fit theory proposes that compatibility between individual and environmental attributes produces optimal employee outcomes, including work adjustment, job satisfaction, organizational commitment, stress and strain, job performance and intention to quit (Dawis and Lofquist, 1984; Kristof-Brown et al., 2005). On the contrary, PE misfit or discrepancies between individual attributes and environment's attributes can reduce positive outcomes (van Vianen, 2018). We will apply PE fit perspective in assessing the impact of the environment (i.e., organizational culture and societal culture) on the relationship between individual-level values and LMX.

In sum, one way to envision the impact of all three levels on the ingroup-outgroup relationship, which determines LMX quality is with a three-dimensional model (Fig. 1). In this model, each axis represents one level-micro, meso, macro-of the total relationship. Using the dimensions specified in Fig. 1 for each level the overall micro, meso, macro impact can be identified by a point in space within this 3D model. However, to fully understand the true impact that each level has on LMX, we unpack the model to test each level separately, as subsequently discussed. 


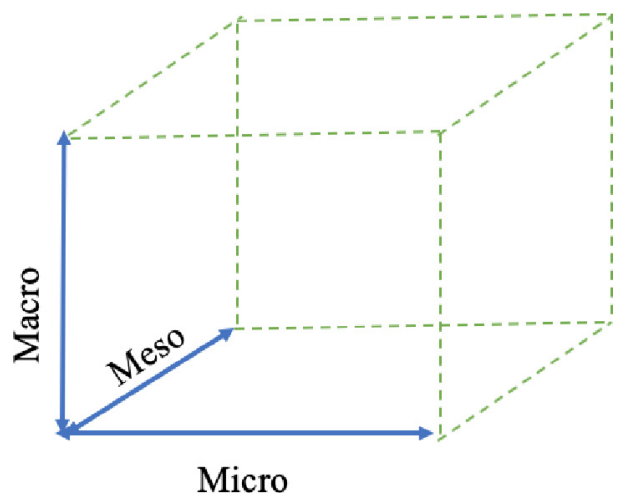

\section{$\underline{\text { STUDY DIMENSIONS }}$}

$\begin{array}{lll}\text { Micro: } & \begin{array}{l}\text { Personal Collectivism } \\ \text { Personal Individualism }\end{array} & \begin{array}{l}\text { (high to low) } \\ \text { (high to low) }\end{array} \\ \text { Meso: } & \begin{array}{l}\text { Clan and Hierarchy } \\ \text { Adhocracy and Market }\end{array} & \begin{array}{l}\text { (high to low) } \\ \text { (high to low) }\end{array} \\ \text { Macro: } & \begin{array}{l}\text { Societal Collectivism } \\ \text { Societal Individualism }\end{array} & \begin{array}{l}\text { (high to low) } \\ \text { (high to low) }\end{array}\end{array}$

Fig. 1. A three-dimensional model of the impact of the micro- (individual values), meso- (organizational culture) and macro-level (societal culture) influences.

\subsection{The micro-level relationships of collectivism and individualism with LMX}

Values are generally defined as criteria that people apply to select and justify actions, or to evaluate themselves, others and events (Kluckhohn and Strodtbeck, 1961). They are individuals' stable preferences serving as a latent but conscious guide of human behaviors (Rokeach, 1973). Individuals' values are considered to be one of the most powerful regulators of human behavior as they not only shape desirable or undesirable behaviors, they also help set goals (Schwartz, 1992, 1994). Among all values dimensions, the two most common ones, are perhaps collectivism and individualism. The key difference between them rests on how one views his/her relationship with others (Hofstede, 1980; Kagicibasi, 1995; Triandis, 1995). Considering this and the dependent variable of our study, LMX, we postulate these two values dimensions should have influence on how members approach their dyadic relationship with their leaders, especially in a cross-cultural context. However, the impact of these values dimensions has rarely been examined in the international LMX literature. Of the 93 international LMX studies selected in Pellegrini's (2015) qualitative review, we can only identify three studies that incorporate values or values dimensions as a study variable. The one by Ashkanasy and O'Connor (1997) examined the relationship between person-to-person values congruence and LMX. They found that supervisor-subordinate similarity in achievement and obedience values were positively associated with the quality of LMX. The second study by Erdogan and Liden (2006) examined the moderating effect of individuals' collectivism in the relationship between member-perceived justice and LMX. They found that individual-level collectivism weakened the relationship between interactional justice and LMX, as collectivism encouraged maintaining harmonious relationships at the expense of individual identities. The third study, by Schaubroeck and Lam (2002), found different group (meso) level values have differentiated roles in personality congruence. Specifically, supervisor-subordinate similarity of personality was positively related to advancement when collectivism within the work unit was high; but, peer similarity of personality was positively associated with promotion when work unit-level individualism was high. The limited number of values-based studies suggests the relationship of values and LMX in the international context is far from being fully explored.

Collectivism and individualism are values constructs that operate at the individual level, apart from the societal level (Schwartz, 1992; Ralston et al., 2014; Triandis, 1995). Individuals who have internalized collectivistic values have an innate need to form relationships with others, as how they relate to others forms a core part of their self-identity (Triandis, 1995). They also have a tendency to form ingroups and differentiate their relationships with members in the ingroup and outgroup. Within an ingroup, they feel obligated to devote their loyalty to other group members without much questioning. They also render trust on ingroup members because of their membership. Collectivists, hence, see self as interdependent with those of the ingroup. They pay a premium to maintain relationships, even to the extent that established relationships are not of their best interest to do so. They see behaviors 
more as a result of external factors, such as norms and roles. They also view interpersonal relationship as stable, with the self being changeable and adaptable to the social environment (Erdogen and Liden, 2006, Triandis, 2001). That is in contrast with individuals who are high on individualism values. Individualistic people tend to be independent in thinking and behavior (Hofstede, 2001; Triandis, 1995; Schwartz, 1992). Individualists have an independent, autonomous, and relatively stable sense of self. They tend to be high on expressiveness, dominance, self-initiation, and aggressiveness. They prefer logic and tend to hold independent opinions. They tend to attribute behaviors to the internal factors of attitudes and personality, and adhere less to societal or ingroup norms. They view achievement as a way to develop their self-esteem which forms the basis of their happiness (Kwan et al., 1997; Uchida et al., 2004). In the event of conflict, they tend to prioritize personal above group goals. Individualists do not have a strong psychological need for maintaining relationships that they do not like or from which they see no benefit (Triandis, 1995).

As we indicate in Section 1, the essence of this dyadic relationship approach to leadership is that leaders tend to develop differentiated relationships with their members and form ingroups and outgroups within an organization (Erdogan and Bauer, 2014; Erdogan and Liden, 2002). Individuals, who have a collectivistic orientation see the importance of relationships, value emotional interdependence (Kagitçibaşi, 1995) and hence have a psychological need to become an ingroup member. This translates into motivation to attend to others' needs, and to fit in and maintain harmonious interdependence (Markus and Kitayama, 1991). Collectivists are motivated to form quality relationship with their leaders. These natural tendencies are aligned with the characteristics of high LMX relationships that involve loyalty, commitment, flexibility and continuous reciprocity (Pellegrini, 2015). We propose that the higher members' collectivistic orientations are, the more they will be willing to expend effort in building positive (ingroup) relationships with their leaders, which in turn results in higher quality LMX (Maslyn and Uhl-Bien, 2001). Conversely, the individualist orientation is not aligned with ingroup orientation. Individualists see themselves as independent selves. They tend to be expressive and forthright with their own views. Being an outgroup member with the leader does not make them feel insecure in the workplace. Thus, individualists do not view being in an ingroup with the leader as naturally necessary. They do not feel the need to expend effort to form high LMX relationship, unless they see forming such relationships as strategically beneficial to their professional advancement or they truly like their leader. Moreover, it is evident that individualists could trade-off ingroup relationship for maintaining self-esteem (Kwan et al. (1997)). Accordingly, we expect that individual-level individualism is negatively associated with LMX quality (cf. Markus and Kitayama, 1991). Thus, we hypothesize:

Hypothesis 1a. Individual-level collectivism is positively related to LMX quality.

Hypothesis 1b. Individual-level individualism is negatively related to LMX quality.

\subsection{The meso-level relationship of organizational culture with $L M X$}

Organizational culture has been defined as "a pattern of shared basic assumptions that the group learned as it solved its problems of external adaptation and internal integration" (Schein, 2010, p.12). It represents the core set of managerial values and assumptions that define how an organization conducts its business. As presented in Fig. 2, the top left quadrant is the clan culture, next clockwise is the adhocracy culture, bottom right is the market culture and at the bottom left lies the hierarchy culture. As discussed by Cameron and Quinn (1999), a clan culture resembles an extended family in which sharing, teamwork, consensus, loyalty, organizational commitment, trust and concern for people are highly endorsed. While an adhocracy culture endorses flexibility, the essence of the culture is related to entrepreneurship, with freedom, risk taking, uniqueness and innovation being its core values. A market culture emphasizes results and competition, and achievement, goal attainment, aggressiveness and hard-driving for winning are its important values. Lastly, a hierarchy culture centers on structure and control. Excellence is defined by efficiency and smooth operations, which can be achieved by having formal rules and policies in place. Its core values are conformity, stability and security.

An organization's values manifest in the behaviors of its members. This forms the basis of the two mechanisms through which organizational culture can impact LMX quality. First, organizational culture provides schemas for its members (Bartunek and Moch, 1987) to make sense of what is happening in their workplace. Organizational schemas, when internalized, become the mental shortcuts used by members to encode and interpret incoming information. Through this cognitive process, organizational culture impacts members' behavioral choices (Harris, 1994). Second, organizational culture serves as an organization's social control system (O'Reilly and Chatman, 1996). Members are expected to follow what is practiced or avoided. Any deviation of the organizational norms, if noticed, will be corrected (Sørensen, 2002). In terms of PE perspective, organizational culture is part of the proximal environment in which employees operate and with which they interact. If an organization upholds LMX relationship development, members will be motivated to expend effort to develop high quality relationship with their leaders (Erdogan et al., 2006).

From the description in the previous section, we can see that the core values of clan and hierarchy cultures (the left-side quadrants of Fig. 2) are family and loyalty, and conformity, stability and security, respectively. They parallel collectivistic values (Ralston, 2017). On the other hand, the core values of adhocracy and market cultures (the right-side quadrants) are flexibility and freedom, and achievement and goal attainment, respectively which are aligned with individualistic values (Treviño et al., 2020). We can postulate that clan and hierarchy cultures encourage harmonious relationships with supervisors and being an ingroup member is important to employees. On the other hand, adhocracy and market cultures encourage individuality and self-determination, as what defines effectiveness and excellence is based on individualistic behaviors such as being creative, risk taking and goal orientation, values that form the core of individualism. Accordingly, we make a comparable argument for meso-level cultures as we did for microlevel values. Organizations that carry high clan and hierarchy cultural values will likely result in a strong relationship-schema among their members, which in turn will reinforce members' effort in building positive relationship with their leaders. As more members 


\section{FLEXIBILITY/DISCRETION}

\section{Cultural type: Clan}

Dominant attributes: cohesiveness, participation, teamwork, sense of family

Leadership: mentor, facilitator

Bonding: loyalty, tradition, cohesion

Strategy: developing HR, commitment, morale

\section{Cultural type: Adhocracy}

Dominant attributes: entrepreneurship, creativity

Leadership: entrepreneur, innovator, risk-take

Bonding: entrepreneurship, flexibility risk

Strategy: innovation fosters new sources, growth

\section{INTERNAL MAINTENANCE AND} INTERGRATION

\section{Cultural type: Hierarchy}

Dominant attributes: order, regulations, uniformity

Leadership: coordinator, Administrator

Bonding: rules, procedures

Strategy: stability, predictability, smooth operation, control fosters efficiency

\section{EXTERNAL POSITIONING AND DIFFERENTIATION}

\section{Cultural type: Market}

Dominant attributes: Competitiveness, goal achievement

Leadership: decisive, achievement-oriented

Bonding: goal orientation, competition

Strategy: competitive advantage and market superiority

\section{CONTROL/STABILITY}

Fig. 2. Core values and emphases of the four organizational culture types under competing values framework.

commit in relationship building activities, a stronger social force would emerge to encourage others to follow suit. On the other hand, organizations that are high on adhocracy or market cultures will likely carry a high independence-schema that encourages members to seek independence behaviors. We, therefore, hypothesize:

Hypothesis 2a. Clan organizational culture is positively related to LMX quality.

Hypothesis 2b. Hierarchy organizational culture is positively related to LMX quality.

Hypothesis 2c. Adhocracy organizational culture is negatively related to LMX quality.

Hypothesis 2d. Market organizational culture is negatively related to LMX quality.

\subsection{Moderating role of meso-level organizational culture}

Drawing on the maxim that behavior is a function of person and environment (Lewin, 1936/2013), the PE perspective states that the interaction of person and environment matters to various employee outcomes (see Kristof-Brown et al., 2005). In Tett and associates' personality trait-based interactionist model, a PE derivative, (Tett and Burnett, 2003; Tett and Guterman, 2000), organization, in addition to social and task, is one of the three major sources that provides trait-relevant cues to moderate the relationship between personality trait and work behavior. If we treat individual-level collectivism and individualism as personality traits (cf. Triandis, 1995), we would postulate that organizational culture, the meso-level cultural environment for employees, in which individual values are nested, would have a moderating effect on the values-behavior relationship. Furthermore, if individuals in the organization are surrounded by similar others, as opposed to dissimilar others, the impact of their values on behavior would be exacerbated through receiving peer support and thereby reinforcement provided by the similar others (O'Reilly and Chatman, 1996).

Viewing values congruence as PE fit (e.g. Cable and Judge, 1996; O'Reilly et al., 1991), we posit that individuals who find values congruence or fit in the organization, will experience higher validation of their perspectives and beliefs and hence higher values fulfilment (Van Vianen, 2000). We expect that individuals' values-driven behavior will be amplified in an environment that encourages similar values. Conversely, in the misfit situation that does not encourage similar values, or where there are no compatible organizational norms that further approve the values-driven behavior, individuals' values-driven behavior will be suppressed.

As discussed in Section 2.3, we posit that clan and hierarchy cultures are congruent with collectivistic values, and adhocracy and market cultures are congruent with individualistic values (Ralston, 2017). Individuals high on collectivistic values would find support 
of their values priority or situational cues in a clan or hierarchy organizational environment. Specifically, in regard to LMX, these individuals would find normative endorsement of joining the ingroup of the leaders and exerting more efforts towards relationship building behavior. Conversely, individuals who are high on collectivistic values would experience less values fulfilment and less peer support in an adhocracy or market environment, as these environments reject their values priorities. Similarly, we propose that the negative impact of individualism on LMX would be strengthened in an adhocracy or market culture, as these organizational cultures are aligned with individualistic values and behaviors. Concurrently, the negative impact of individualism on LMX in a clan or hierarchy culture would serve to weaken the relationships in these organizational environments.

Thus, we, hypothesize:

Hypothesis 3a. Clan and/or hierarchy culture moderates the relationship between individual-level collectivism and LMX, such that when clan and/or hierarchy culture is stronger, the positive relationship between individual-level collectivism and LMX will be greater.

Hypothesis 3b. Clan and/or hierarchy culture moderates the relationship between individual-level individualism and LMX, such that when clan and/or hierarchy culture is stronger, the negative relationship between individual-level individualism and LMX will be weaker.

Hypothesis 3c. Adhocracy and/or market culture moderates the relationship between individual-level individualism and LMX, such that when adhocracy and/or market culture is stronger, the negative relationship between individual-level individualism and LMX will be greater.

Hypothesis 3d. Adhocracy and/or market culture moderates the relationship between individual-level collectivism and LMX, such that when adhocracy and/or market culture is stronger, the positive relationship between individual-level collectivism and LMX will be weaker.

\subsection{The moderating role of societal-level collectivism and individualism}

We are also interested in identifying the influence of societal environment on the relationship between individual-level values and LMX. Similar to Hypothesis 3, we posit that if the values of the society and the individual align, the impact of an individual's values on LMX will be greater, whereas if the values in the society contradict those of the individual, the impact of individual's values on LMX will be weaker. We postulate, as such, because individuals' individualistic tendencies are endorsed and promoted in an individualistic society but discouraged and disapproved in a collectivist society. Similarly, individuals' collectivistic tendencies are in harmony with the societal values in a collectivist society but in conflict with the societal values in an individualist society. Drawing on PE fit theory (Kristof-Brown et al., 2005; Yu, 2013), individuals have an innate need to adapt to their environment so as to belong, take control of their life, and reduce inconsistency and stress to secure life satisfaction and happiness. In PE fit situations where the society's values and individual's values are congruent, the individual receives natural endorsement of his/her intended behavior and therefore higher motivation to pursue the intended action. In essence, the individual displays conformity. In misfit situations where the individual's values and the society's values are not congruent, the individual would need to make adjustments and adapt his/her personal values and workplace behavior to conform to the larger society's expectations, if the individual wishes to fit the norms of the society. Therefore, we postulate that individual-level collectivism would be reinforced in a collectivist culture but suppressed in an individualist culture, while individual-level individualism would be reinforced in an individualist culture but suppressed in a collectivist culture. Taken together, we hypothesize:

Hypothesis 4a. Societal-level collectivism will moderate the positive relationship of individual-level collectivism and LMX such that when societal-level collectivism is higher, the positive relationship will be greater.

Hypothesis 4b. Societal-level collectivism will moderate the negative relationship of individual-level individualism and LMX such that when societal-level collectivism is higher, the negative relationship will be weaker.

Hypothesis 4c. Societal-level individualism will moderate the positive relationship of individual-level collectivism and LMX such that when societal-level individualism is higher, the positive relationship will be weaker.

Hypothesis 4d. Societal-level individualism will moderate the negative relationship of individual-level individualism and LMX such that when societal-level individualism is higher, the negative relationship will be greater.

\section{Methods}

\subsection{Sample and procedures}

Our sample comprised 2343 participants from two occupations (business professionals and k-12 schoolteachers) within six countries. We collected these data in each country over a period of not more than three months. As shown in Table 1, the six countries in our sample are: China, Mexico, the Netherlands, Russia, Spain and the U.S. Based on Ronen and Shenkar's (2013) 11-regional clusters of the world culture map, these countries represent six of these clusters: (1) Confucian (China), (2) Latin America (Mexico), (3) Nordic (Netherlands), (4) Eastern Europe (Russia), (5) Latin Europe (Spain) and (6) Anglo (U.S.). The six countries also broadly 
Table 1

Data collection locations.

\begin{tabular}{|c|c|c|c|c|c|c|}
\hline Country & $\begin{array}{l}\text { China } \\
(n=406)\end{array}$ & $\begin{array}{l}\text { Mexico } \\
(n=359)\end{array}$ & $\begin{array}{l}\text { Netherlands } \\
(n=394)\end{array}$ & $\begin{array}{l}\text { Russia } \\
(n=307)\end{array}$ & $\begin{array}{l}\text { Spain } \\
(n=449)\end{array}$ & $\begin{array}{l}\text { U.S. } \\
(n=428)\end{array}$ \\
\hline City/Region & $\begin{array}{l}\text { Beijing } \\
\text { Changsha } \\
\text { Qingdao } \\
\text { Shanghai }\end{array}$ & $\begin{array}{l}\text { Guanajuato y } \\
\text { Querétaro } \\
\text { (Central Mexico) }\end{array}$ & $\begin{array}{l}\text { Nijmegen } \\
\text { (Eastern Netherlands) }\end{array}$ & $\begin{array}{l}\text { Moscow } \\
\text { St. Petersburg } \\
\text { Tatarstan } \\
\text { Leningrad } \\
\text { Omsk } \\
\text { Oblast } \\
\text { Novosibirsk }\end{array}$ & $\begin{array}{l}\text { Valencia region } \\
\text { (Eastern Spain) }\end{array}$ & $\begin{array}{l}\text { Atlanta } \\
\text { Chicago } \\
\text { Miami } \\
\text { New Orleans } \\
\text { San Francisco }\end{array}$ \\
\hline
\end{tabular}

comprised three individualist countries (Netherlands, Russia and U.S.) and three collectivist countries (China, Mexico and Spain).

Using two occupations in six countries, we formed a twelve-society sample. The twelve-society sample is justified because teachers and business professionals share different sub-cultures. Teachers tend to be relatively high on collectivism with the goal of helping others, while business professionals tend to be relatively high on individualism with the goal of doing well for themselves (Triandis and Singelis, 1998). We believe grouping respondents by country and profession is meaningful to address within-nation differences in cultural orientations because profession is a valid cultural delineator (Taras et al., 2016) in addition to political boundaries that mark the borders of different countries (Peterson et al., 2012).

Following the data collection and data management advice for cross-cultural studies from Karam and Ralston (2016), we only kept those participants who grew up (spent five years or more before the age of 15) in their respective countries. Table 2 provides information of sample sizes and other demographic characteristics (age, gender, education level, position and company size) for the occupation/country samples.

The data collection process was consistent across all six countries. Local collaborators either hand-delivered or sent a paper questionnaire to participants' workplace by mail. A pre-addressed and stamped envelope was included in the survey package for participants to return the completed questionnaire. All participation was voluntary. Moreover, participants were instructed not to put their names on the questionnaire to maintain their anonymity. Also, they were assured that there were no right or wrong answers, and we were only interested in their opinions. The response rate ranged from 14 to $17 \%$ across all samples.

\subsection{Measures}

We first prepared the questionnaire for this study in English. The local collaborators followed the standard translation and backtranslation procedures to convert the survey questionnaire from English into Chinese, Spanish, Russian or Dutch (Brislin, 1986).

Table 2

Sample characteristics.a

\begin{tabular}{|c|c|c|c|c|c|c|c|c|c|c|}
\hline \multirow[t]{2}{*}{ Country } & \multirow[t]{2}{*}{ Group } & \multirow[t]{2}{*}{$\mathrm{N}$} & \multicolumn{2}{|l|}{ Age } & \multirow[t]{2}{*}{ Gender (\% Female) } & \multirow[t]{2}{*}{ Education Level (Mean) } & \multirow[t]{2}{*}{ Position (\% professional) } & \multicolumn{3}{|c|}{ Company size $^{\mathrm{a}}(\%)$} \\
\hline & & & Mean & (S.D.) & & & & $<100$ & $100-1000$ & $>1000$ \\
\hline \multirow[t]{3}{*}{ China } & Total & 406 & 31.9 & $(5.9)$ & 72 & 2.9 & 71 & 45 & 39 & 16 \\
\hline & Manager & 228 & 31.3 & $(5.2)$ & 68 & 3.1 & 55 & 34 & 40 & 26 \\
\hline & Teacher & 178 & 32.7 & $(6.6)$ & 75 & 2.7 & 92 & 59 & 38 & 3 \\
\hline \multirow[t]{3}{*}{ Mexico } & Total & 359 & 35.8 & (10.6) & 50 & 3.0 & 72 & 62 & 26 & 12 \\
\hline & Manager & 182 & 35.0 & (10.9) & 51 & 2.8 & 62 & 53 & 31 & 16 \\
\hline & Teacher & 177 & 36.6 & (10.2) & 49 & 3.1 & 82 & 72 & 21 & 8 \\
\hline \multirow[t]{3}{*}{ Netherlands } & Total & 394 & 35.6 & (11.5) & 47 & 3.0 & 58 & 28 & 19 & 53 \\
\hline & Manager & 220 & 34.8 & $(9.3)$ & 46 & 3.1 & 58 & 28 & 19 & 53 \\
\hline & Teacher & 174 & 36.7 & (13.8) & 48 & 3.0 & n.a. & n.a. & n.a. & n.a. \\
\hline \multirow[t]{3}{*}{ Russia } & Total & 307 & 41.3 & $(10.8)$ & 63 & 3.8 & 26 & 55 & 33 & 12 \\
\hline & Manager & 216 & 40.2 & $(9.8)$ & 50 & 4.0 & 17 & 41 & 41 & 18 \\
\hline & Teacher & 91 & 44.0 & (12.5) & 93 & 3.3 & 52 & 87 & 13 & 0 \\
\hline \multirow[t]{3}{*}{ Spain } & Total & 449 & 37.7 & $(9.7)$ & 61 & 3.0 & 80 & 50 & 29 & 22 \\
\hline & Manager & 270 & 36.5 & $(9.2)$ & 61 & 2.9 & 74 & 42 & 33 & 26 \\
\hline & Teacher & 179 & 39.5 & (10.0) & 63 & 3.2 & 88 & 62 & 23 & 15 \\
\hline \multirow[t]{3}{*}{ USA } & Total & 428 & 38.6 & (11.8) & 55 & 3.4 & 49 & 33 & 40 & 27 \\
\hline & Manager & 186 & 36.1 & (11.6) & 49 & 3.2 & 37 & 37 & 28 & 34 \\
\hline & Teacher & 246 & 40.5 & (11.6) & 60 & 3.6 & 58 & 29 & 49 & 21 \\
\hline \multirow[t]{3}{*}{ TOTAL } & TOTAL & 2343 & 36.7 & (10.6) & 58 & 3.2 & 61 & 46 & 32 & 22 \\
\hline & Manager & 1302 & 35.6 & $(9.8)$ & 55 & 3.2 & 51 & 39 & 32 & 29 \\
\hline & Teacher & 1041 & 38.0 & (11.4) & 62 & 3.2 & 75 & 57 & 32 & 11 \\
\hline
\end{tabular}

Notes: Education attainment was coded as $1=8$ or fewer years completed; $2=9-12$ years completed; $3=$ Bachelor degree; $4=$ Masters degree; $5=$ Doctoral degree; n.a. $=$ not available. The choices for the question of position comprised professional, first-level manager, second-level manager, and upper-level manager.

a Refer to the number of employees in the organization. 
Regarding response format, we used nine-point Likert type ( $1=$ strongly disagree; $9=$ strongly agree) for both LMX and organizational culture measures, and followed the specific response format ( -1 to 7$)$ for individualism and collectivism, with more details are provided in subsequent sections.

\subsubsection{Leader-member exchange}

We used the adapted version of LMX-7 scale, originally developed by Scandura and Graen (1984), with strongly disagree and strongly agree response anchors to measure how a subordinate perceives the relationship quality with his or her immediate supervisor (Bauer and Green, 1996; Graen and Uhl-Bien, 1995; Liden et al., 1993). Despite criticism of the scale's discriminant validity and its psychometric properties in U.S. samples (Schriesheim and Cogliser, 2009; Schriesheim et al., 2011), LMX-7 had been the most adopted LMX scale in comparative studies (e.g. Chong et al., 2015; Selvarajan et al., 2018), and has been found to have high correlations with the other widely used scale, the 12-item LMX-MDM (Liden and Maslyn, 1998) in global LMX assessment (Joseph et al., 2011; Liden et al., 2015). Dulebohn et al.'s (2012) meta-analysis also identified that LMX-7 and LMX-MDM correlated highly and presented a consistent pattern of relationships with the same antecedents and outcomes. A sample item of this scale is "My immediate supervisor understands my problems and needs."

\subsubsection{Individualism and collectivism}

We used the 45 Schwartz Values Survey (SVS) items deemed appropriate for cross-cultural analysis (Schwartz, 1992, 1994) to measure respondents' individualism and collectivism. The SVS has been validated across 70 countries (Schwartz, 2006). These 45 items are considered as universal values and form ten universal values types in a circumplex model (Schwartz, 1992, 2006). Respondents were asked to rate the importance of each basic values item as their guiding principle in life on a nine-point scale $(-1$ [opposed to my values] to 7 [of supreme importance in my guiding principles]). For individualism, we used the 18 values items that form the values types of self-direction, stimulation, hedonism, achievement, and power (Schwartz, 1994). Sample items include independent, a varied life, pleasure, ambitious and authority. For collectivism, we used the 14 items that form the values types of conformity, tradition and benevolence (Schwartz, 1994). Sample items are obedience, respect for tradition and loyalty.

\subsubsection{Organizational culture}

We used the Organizational Culture Assessment Instrument (OCAI; Cameron and Quinn, 1999) to assess respondents' perceptions of their organization's culture. The OCAI questionnaire comprised 24 short scenarios related to six aspects of organizational effectiveness - dominant organizational characteristics, organizational leadership style, management of employees, organizational glue, strategic emphasis and criteria for success. The scores of each cultural sub-dimension are the means of the relevant six items for clan, adhocracy, market and hierarchy cultures, respectively. A sample scenario for clan culture is, "The organization is a very personal place. It is like an extended family. People seem to share a lot of themselves." For adhocracy culture, "The leadership in the organization is generally considered to exemplify entrepreneurship, innovating or risk taking." For market culture, "The management style is characterized as hard-driving competitiveness, high demands and achievement." For hierarchy culture, "The glue that holds the organization together is formal rules and policies. Maintaining a smooth-running organization is important."

\subsubsection{Control variables}

We incorporated the demographics (age, gender, education level, company size and position) commonly used in international values research in our questionnaire (World Values Survey, 2019; Ralston et al., 2011, 2014). Unfortunately, the data for company size and position was not available for all sub-samples. Thus, we only used age, gender and education as covariates in our analysis. Using these covariates is reasonable as age, gender and education were found to significantly influence the effect sizes of cultural values main effects according to the meta-analysis of Taras et al. (2010). We reported all demographics in the descriptive statistics in Table 2.

\subsection{Analytical strategy}

We performed our analyses using STATA 15. First, we established measurement invariance of our model using multigroup CFA. Next, we applied hierarchical linear modelling (HLM) intercepts-as-outcomes procedures (Raudenbush and Bryk, 2002) to test our study's hypotheses. The intraclass correlation coefficient (ICC) estimate, after running the null model, indicated that $11.1 \%$ of the variation of LMX was attributed to differences between groups. According to Hox (2010), ICC of 10\% indicates a medium-sized nesting effect for organizational research. Moreover, HLM is superior to single-level regression models and able to provide more accurate estimates, as the latter ignores the nested structure of the data and wrongly assumes independence of the observations and randomness of errors. For these reasons, we proceeded with HLM. In our two-level HLM models, the level-1 (individual-level, hereafter) variables comprised demographic covariates (age, gender and education) and predictors (individual-level collectivism and individualism, and perceptions of organizational culture types [clan, adhocracy, market and hierarchy]), and the dependent variable, LMX. Level-2 (societal-level, hereafter) variables consisted of societal-level collectivism and individualism. To ensure the scales of collectivism and individualism could be aggregated to form societal-level predictors, we computed the interrater agreement (IRA) index scores, $\alpha w g(J)$. The IRA statistics ranged from 0.80 to 0.97 for collectivism and 0.82 to.97 for individualism across all subsamples, meeting threshold of 0.70 (LeBreton and Senter, 2008). Lastly, we group-mean centered all individual-level predictors and grand-mean centered the societal-level predictors before entering them in the HLM analysis. 
Table 3

Means, standard deviations and correlation coefficients of study variables.

\begin{tabular}{|c|c|c|c|c|c|c|c|c|c|c|c|}
\hline & Mean & S.D. & 1 & 2 & 3 & 4 & 5 & 6 & 7 & 8 & 9 \\
\hline 1. LMX & 6.08 & 1.26 & & & & & & & & & \\
\hline 2. Individualism & 4.34 & 0.45 & 0.03 & & & & & & & & \\
\hline 3. Collectivism & 4.54 & 0.60 & 0.01 & $-0.70^{* * *}$ & & & & & & & \\
\hline 4. Clan & 6.08 & 1.06 & $0.22^{* * *}$ & $-0.08^{* * *}$ & $0.08^{* * *}$ & & & & & & \\
\hline 5. Adhocracy & 5.45 & 1.00 & $-0.12^{* * *}$ & -0.03 & 0.00 & $-0.10^{* * *}$ & & & & & \\
\hline 6. Market & 5.74 & 1.08 & $-0.21 * * *$ & $0.13^{* * *}$ & $-0.09^{* * *}$ & $-0.73^{* * *}$ & $-0.07^{* *}$ & & & & \\
\hline 7. Hierarchy & 6.02 & 0.69 & $0.09 * * *$ & -0.03 & 0.01 & $-0.17^{* * *}$ & $-0.68^{* * *}$ & $-0.24 * * *$ & & & \\
\hline 8. Age & 36.69 & 10.58 & 0.01 & $-0.23^{* * *}$ & $0.11^{* * *}$ & $0.05^{*}$ & -0.01 & $-0.08^{* * *}$ & 0.03 & & \\
\hline 9. Gender & 1.58 & 0.49 & $0.05^{*}$ & $-0.15^{* * *}$ & $0.07 * * *$ & $0.08^{* * *}$ & -0.01 & $-0.08^{* * *}$ & 0.01 & $-0.07 * * *$ & \\
\hline 10. Education & 3.18 & 0.78 & $0.11^{* * *}$ & $0.13^{* * *}$ & $-0.09 * * *$ & 0.03 & $-0.08 * * *$ & -0.00 & 0.04 & $0.12^{* * *}$ & $-0.05^{*}$ \\
\hline
\end{tabular}

Notes: $* p<.05 ; * * p<.01 ; * * * p<.001$.

Codes for Age: values as reported; Gender $(1=$ male; $2=$ female); Education $(1=8$ or fewer years completed; $2=9-12$ years completed; 3 = Bachelor degree; 4 = Master degree; 5 = Doctoral degree).

\subsection{Managing common method variance}

Participants reported their self-evaluation of collectivism, individualism and their perceptions of organizational culture and relationship quality with their immediate supervisors. A research design to avoid common method variance would have been to assess the independent variable, i.e. values, and the moderator by perceptions of participants, and the dependent variable, LMX, by participants' immediate supervisors. That said, for large-scale research of this kind (e.g. Chong et al., 2015; Ralston et al., 2006, 2011, 2014; World Values Survey Association, 2019), it is common and practical to have only one source of data. In fact, in most of the LMX studies, LMX was measured by the perceptions of subordinates instead of leaders (Dulebohn et al., 2012). We, nevertheless, acknowledged the possibility of common method variance. To minimize it, we followed the ex-ante and ex post methods as recommended by Podsakoff, MacKenzie and Podsakoff et al. (2003).

\section{Results}

Table 3 provides the means, standard deviations and correlation coefficients of the study and demographic variables. LMX had a positive correlation with clan culture $(r=0.22, p<.001)$, hierarchy culture $(r=0.09, p<.001)$ and education $(r=0.11$, $p<.001)$, and a negative correlation with market culture $(r=-0.21, p<.001)$ and adhocracy culture $(r=-0.12, p<.001)$. As shown in Table 4, all of the study variables in the pooled sample had good internal consistency, with Cronbach's alphas values ranging from 0.79 to 0.92 . The 84 alphas of the subsample variables met the threshold of 0.70 , except three - individualism and collectivism for Russian business professionals ( 0.61 and 0.58 , respectively), and hierarchy culture for Russian teachers (0.62). Following the multi-country studies of Fu et al. (2004) and Ralston et al. (2011, 2014), having a few sub-samples with an alpha in the range of 0.5 to 0.6 for large-scale cross-cultural studies is considered acceptable.

Prior to conducting multigroup confirmatory factor analysis, we followed the procedures of Nunnally and Bernstein (1994) to reduce the numbers of parameters estimated in the measurement models. This process is necessary for models involving large numbers of indicators and factors and to address computation limitations. In our case, our measurement model had 63 indicators and seven factors. We derived three indicators for each of the seven multi-item measures. We did so by averaging the items with highest and lowest loadings to obtain the first indicator, and the next highest and lowest loadings for the second indicator and so forth. We repeated this procedure until all items were assigned to one of the three indicators for each measure. This item reduction method was

Table 4

Cronbach's alphas of study variables by sub-sample.

\begin{tabular}{|c|c|c|c|c|c|c|c|c|}
\hline Country & Sample & LMX & Individualism & Collectivism & Clan & Adhocracy & Market & Hierarchy \\
\hline \multirow[t]{2}{*}{ China } & Manager & 0.90 & 0.84 & 0.83 & 0.87 & 0.85 & 0.76 & 0.76 \\
\hline & Teacher & 0.84 & 0.85 & 0.86 & 0.89 & 0.84 & 0.80 & 0.76 \\
\hline \multirow[t]{2}{*}{ Mexico } & Manager & 0.87 & 0.85 & 0.80 & 0.85 & 0.87 & 0.88 & 0.78 \\
\hline & Teacher & 0.92 & 0.78 & 0.78 & 0.79 & 0.80 & 0.77 & 0.76 \\
\hline \multirow[t]{2}{*}{ Netherlands } & Manager & 0.89 & 0.84 & 0.83 & 0.82 & 0.84 & 0.89 & 0.77 \\
\hline & Teacher & 0.91 & 0.84 & 0.83 & 0.89 & 0.81 & 0.84 & 0.74 \\
\hline \multirow[t]{2}{*}{ Russia } & Manager & 0.95 & 0.61 & 0.58 & 0.90 & 0.92 & 0.93 & 0.90 \\
\hline & Teacher & 0.89 & 0.88 & 0.90 & 0.89 & 0.80 & 0.80 & 0.62 \\
\hline \multirow[t]{2}{*}{ Spain } & Manager & 0.94 & 0.88 & 0.84 & 0.87 & 0.83 & 0.83 & 0.74 \\
\hline & Teacher & 0.94 & 0.86 & 0.87 & 0.82 & 0.74 & 0.86 & 0.70 \\
\hline \multirow[t]{2}{*}{ US } & Manager & 0.93 & 0.90 & 0.89 & 0.87 & 0.88 & 0.87 & 0.80 \\
\hline & Teacher & 0.95 & 0.88 & 0.89 & 0.91 & 0.88 & 0.85 & 0.80 \\
\hline Total & & 0.92 & 0.85 & 0.84 & 0.87 & 0.86 & 0.86 & 0.79 \\
\hline
\end{tabular}




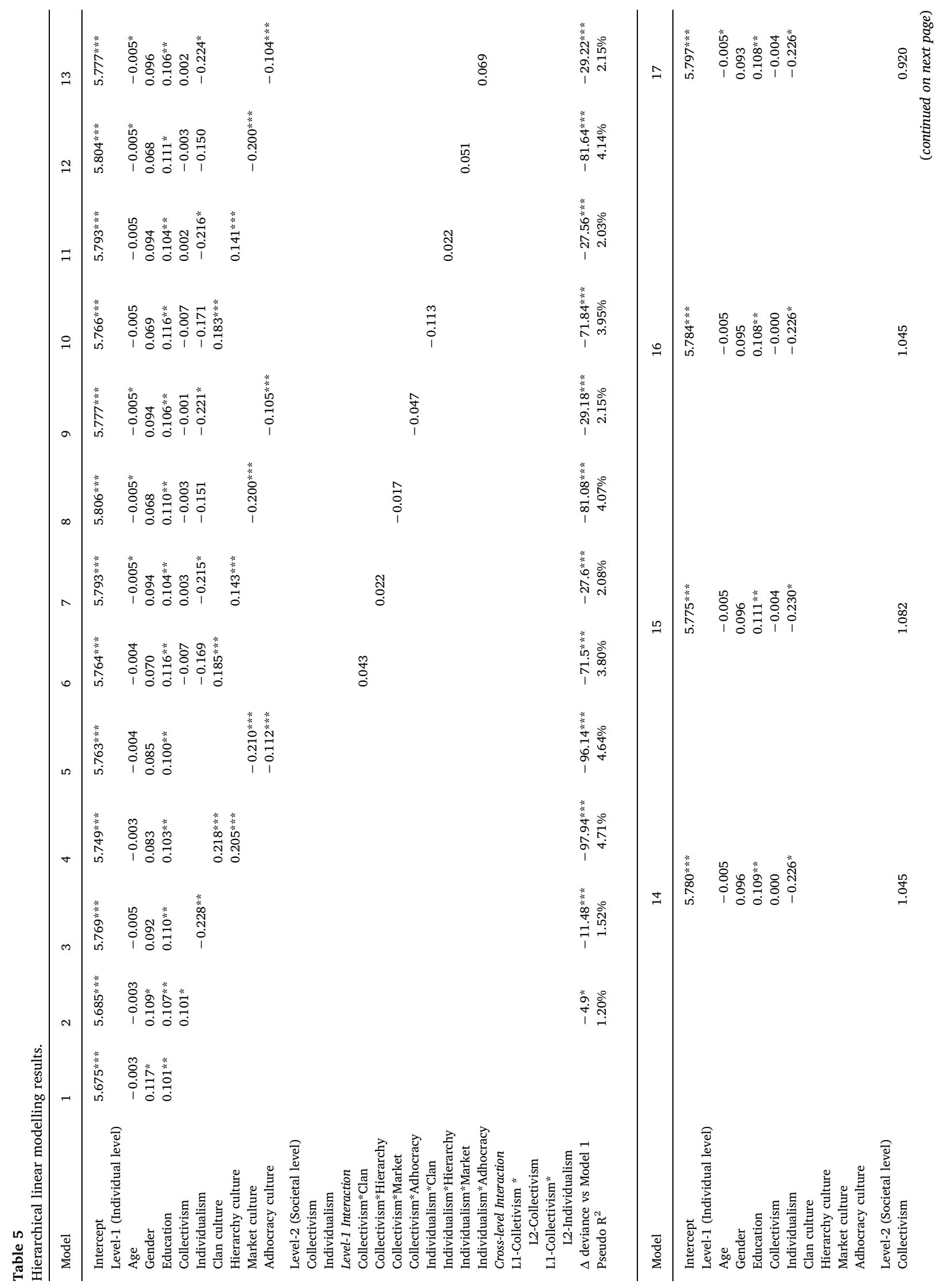




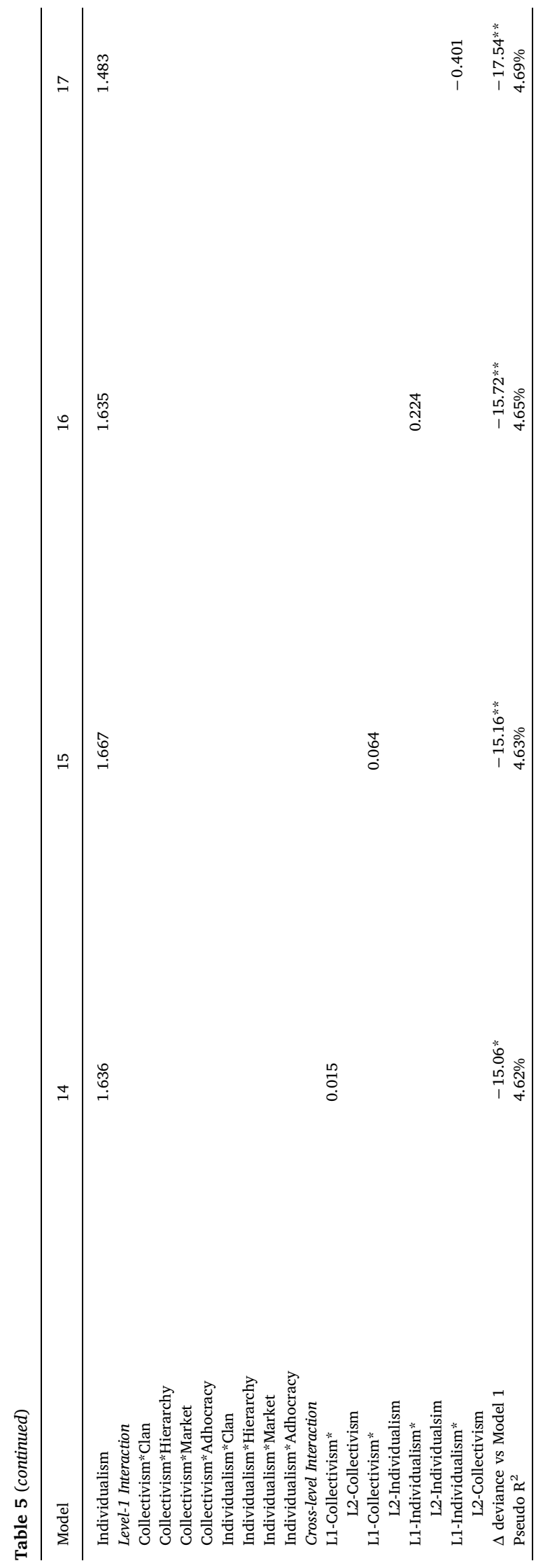


previously used in the LMX study by Eisenberger et al. (2010). The final measurement model had seven factors and 21 indicators. The fit indices indicated the measurement model had acceptable configural invariance across the sub-samples $\left(\chi^{2}=6310.840\right.$, $d f=3048$, RMSEA $=0.073 ; \mathrm{CFI}=0.916, \mathrm{TLI}=0.901 ;$ SRMR $=0.061$ ) but not full metric invariance because of a $\Delta \mathrm{CFI}=-0.011$ between models. We then set free the parameters between the first indicator of market culture for group 1, 3, and 5 which refer to the American, Chinese and Russian manager samples, respectively. The model fit indices indicated sufficient partial metric invariance $(\chi$ ${ }^{2}=6324.326, d f=2956$, RMSEA $\left.=0.076, \mathrm{CFI}=0.908, \mathrm{TLI}=0.897, \mathrm{SRMR}=0.075\right)$ with a $\Delta \mathrm{CFI}=-0.008$ (Cheung and Rensvold, 2002). Further fit indices suggested that our measurement model did not support scalar invariance $\left(\chi^{2}=9926.895\right.$, $d f=3220$, RMSEA $=0.103$; CFI $=0.817$; TLI $=0.811$; SRMR $=0.179$ ). As our study focused on the associations of variables instead of comparing mean values, it was considered appropriate to proceed with analyses with only partial metric invariance of the measurement models (Boer et al., 2018). We followed Hanges (2004) procedures to use within-subject standardized scores in our analyses. Lastly, to examine if common method variance would be a concern, we put all 21 indicators into a one-factor model and a three-factor model by grouping all collectivism and individualism indicators as one factor and all four organizational culture indicators as the second factor in addition to the factor of leader-member exchange. The fit indices for the one factor model $\left(\chi^{2}=25,972.255, d f=3300\right.$, RMSEA $=0.186, \mathrm{CFI}=0.418, \mathrm{TLI}=0.366$, SRMR $=0.194)$, and those of the three factor model $\left(\chi^{2}=13,194.496, d f=3264\right.$, RMSEA $=0.124, \mathrm{CFI}=0.745$, SRMR $=0.109)$ indicated that both alternative models were inferior to the seven-factor model. Therefore, we concluded that common method variance was not likely to be a severe concern.

Table 5 provides the results of HLM analyses. As shown in Model 2, individual-level collectivism was positively related to LMX $(b=0.101, p<.05)$. The findings in Model 3 indicated that individual-level individualism was negatively related to LMX $(b=-0.228, p<.001)$. Thus, H1a and H1b were supported. As shown in Model 4, clan culture was found positively associated with LMX quality $(b=0.218, p<.001)$ and so was hierarchy culture $(b=0.205, p<.001)$. In Model 5 , both adhocracy $(b=-0.112$, $p<.001)$ and market $(b=-0.211, p<.001)$ cultures were found negatively related with LMX. Therefore, H2a, H2b, H2c and H2d were all supported. However, none of the four organizational culture types had any interaction effect with individual values (Models 6-13). Thus, none of Hypotheses 3 was supported. Lastly, neither societal collectivism nor societal individualism had any interaction effect on the individual values-LMX relationship. Therefore, none of Hypotheses 4 was supported (Models 14-17). Table 6 summarizes these findings.

As our sample size of the group level (12) is small, we re-ran our models using Bayesian statistics with STATA 15. Instead of getting one estimate of each parameter in each model with maximum likelihood estimating method, we obtained 10,000 Markov Chain Monte Carlo (MCMC) estimates for each parameter in each model with Bayesian analysis. As shown by the posterior medians of estimates of the concerned parameters and the equal-tailed $95 \%$ credible intervals, the findings from the Bayesian models are the same as in the models estimated with maximum likelihood method. That concludes that our results are robust.

\section{Discussion}

In this study, we answer the call for more cross-cultural leadership research (e.g. Dickson et al., 2003; Hanges et al., 2016; Watts et al., 2020). We do so by providing a multicultural, multilevel investigation of the leader-member exchange fit, and to the best of our knowledge, this is the first multi-level, multi-group investigation of LMX. As stated in Section 1.1, we had two primary goals: (1) to investigate the main effects on LMX at the individual and organizational levels; and (2) to investigate possible organizational- and/or societal-level moderating effects on an LMX relationship. To this end, we explored the means and the extent to which individual values, embedded in organizational-level culture and societal-level culture, impacted LMX quality.

Table 6

Support for the LMX hypotheses.

\begin{tabular}{|c|c|c|}
\hline Hypotheses & Direction predicted & Support for hypothesis \\
\hline \multicolumn{3}{|c|}{ Individual-Level (main effect) } \\
\hline Hypothesis 1a & Collectivism - positive & Supported \\
\hline Hypothesis 1b & Individualism - negative & Supported \\
\hline \multicolumn{3}{|c|}{ Organizational-Level (main effect) } \\
\hline Hypothesis 2a & Clan - positive & Supported \\
\hline Hypothesis 2b & Hierarchy - positive & Supported \\
\hline Hypothesis 2c & Market - negative & Supported \\
\hline Hypothesis 2d & Adhocracy - negative & Supported \\
\hline \multicolumn{3}{|c|}{ Organizational-Level (moderating effect) } \\
\hline Hypothesis 3a & Clan or Hierarchy - strengthen collectivism-LMX & Not supported \\
\hline Hypothesis 3b & Clan or Hierarchy - weaken individualism-LMX & Not supported \\
\hline Hypothesis 3c & Market or Adhocracy - strengthen individualism-LMX & Not supported \\
\hline Hypothesis 3d & Market or Adhocracy - weaken collectivism-LMX & Not supported \\
\hline Hypothesis 4a & Societal collectivism - strengthen collectivism-LMX & Not supported \\
\hline Hypothesis 4b & Societal individualism - weaken collectivism-LMX & Not supported \\
\hline Hypothesis $4 \mathrm{c}$ & Societal individualism - strengthen individualism-LMX & Not supported \\
\hline Hypothesis 4d & Societal collectivism - weaken individualism-LMX & Not Supported \\
\hline
\end{tabular}


We found that individual-level values and organizational-level culture had significant main effects on LMX. However, neither organizational-level culture nor societal-level culture exhibited a moderating effect on the individual-level values-LMX relationship. In the context of our three-dimensional theoretical model of the impact of micro-, meso-, and macro-level influences on LMX (Fig. 1), the empirical findings based on our available data suggest that a two-dimensional model might be more appropriate. As our findings show, only the micro (individual-level) and meso (organizational-level) findings were significant.

Candidly, we should not be overly surprised by these findings, as a prior meta-analysis (Taras et al., 2010) found that the most common moderators for values-attitudes or values-behaviors main effects are the demographic control variables (age, gender and education), which we included in our study. While it was not our primarily goal to test the moderating effects of these three demographic variables, we did a series of post hoc analyses to examine if age, gender and/or education "amplified" the values-LMX relationships (Gelfand et al., 2008). We found that none of the demographic variables had a significant moderating effect in the values-LMX relationships (with $p$-values ranging from 0.08 to 0.844 ). The absence of our hypothesized moderating effects could reflect the complexity of the meso-level and macro-level culture constructs. Common cultural constructs, including the two measures we used, do not provide information of culture strength. Organizational culture strength refers to the extent to which norms and values are "widely shared and strongly held" throughout the organization (O'Reilly and Chatman, 1996, p.166). Similarly, the strength of societal culture, operationalized as societal tightness-looseness, refers to the "strength of social norms and degree of sanctioning with societies" (Gelfand et al., 2006, p.6). Cultural strength constructs complement the meso-level and macro-level culture measures that focus on the cultural content or cultural types (Sørensen, 2002) by explicitly considering the strength of the norms and constraints imposed by the respective environment. We recommend that future research incorporates culture strength in their multi-level, multi-cultural research designs to assess the full perspective of the culture effects (Gelfand et al., 2006; Heskett and Kotter, 1992). With that said, our finding that meso-level and societal-level values did not moderate the individual values-LMX main effect does not preclude that there might not be other contextual variables that could be explored in the values-LMX relationship.

Nonetheless, the absence of any interaction between individual values and either organizational or societal culture does provide preliminary evidence that our direct findings might be global and unencumbered by meso or macro factors. This result corresponds to the Adler and Gundersen (2007) assertion that employees bring their values into the organization, and they could be so strong that organization culture cannot diminish it. Similar to the discussion on cultural strength in the previous paragraph, as we did not measure the strength of culture at the individual level, this poses an opportunity for future empirical research. With that said, when comparing the pseudo $R^{2}$ of Model 4 and 5 with those of Model 2 and 3, we found that organizational-level culture had a slightly stronger direct effect on LMX quality than did individual-level culture. This finding, in our opinion, is of importance because it has a variety of implications for practitioners.

\subsection{Practical implications}

LMX is part of the internal social capital within organizations (Uhl-Bien et al., 2000). That is, LMX enhances trust between employees and their leaders, leading to increased knowledge and resource sharing and hence team and organizational performance. It is encouraged within organizations, as it has been found to be associated with desirable follower outcomes and leader effects on members, teams and organizations (e.g., Atwater and Carmeli, 2009; Purcell and Kinnie, 2007; Zhang et al., 2012). Our research findings point to a variety of practical implications for those supervisors who seek to develop higher LMX relationships with their followers. For example, supervisors need to be aware of the cultural heterogeneity within a society and thus the need for them to be flexible with their leadership style. Specifically, followers vary in their level of collectivistic and/or individualistic orientations and tendencies. While collectivist followers tend to form higher LMX quality relationships, leaders may need to invest more effort in building relationships with followers who are high on individualism. Likewise, leaders should also not overlook the potential and performance of their independent-thinking individualistic followers who have a relatively low LMX quality relationship with them. That is, individualistic employees might be more creative, as they do not have a strong need to conform. Moving on, we should remember that organizational-level antecedents are important to an LMX quality relationship. Supervisors working in an adhocracy or market organizational culture would need to exert more effort in building relationships with their followers because the organization's individualistic orientation does not naturally encourage internal relationship building.

\subsection{Limitations and future research directions}

\subsubsection{Limitations}

While there are limitations to our study, as in all research, a positive aspect of these is that future studies can be developed to address the issues that were outside the scope of our study. First, we acknowledge that apart from values, there may be other member variables that impact LMX quality. One such variable may be members' instrumental motivation in building quality relationship with leaders. In Kwan et al. (1997), independent self-construal, an indicator of individual-level individualism, was found positively correlated with relationship harmony. As they explained, achieving interpersonal harmony required self-directed attention and deliberate investment of personal resources, such as time and efforts. These actions are consistent with individualists' self-directedness orientation (Schwartz, 1992). Future studies may also consider controlling for instrumental variables such as self-directedness or upward influence tactics (Ralston and Pearson, 2010) to allow a more precise analysis.

Second, we had a cross-sectional research design and relied on single-source data reported by members. Even though memberrated LMX has been the most popular data collection method among LMX studies (Dulebohn et al., 2012), a two-source or longitudinal data collection method would help reduce the possibility of common method variance and strengthen the claim for causality. 
Third, our sample was somewhat limited in size, thus potentially limiting the generalizability of our findings. Future international research could collect data from a larger group of societies. That said, a research design of this kind would be substantially resourcedemanding and require significant international collaboration, planning and time involvement (Karam and Ralston, 2016).

Fourth, LMX is a distal outcome of values following the values-attitude-behavior hierarchy (Homer and Kahle, 1988). There could be other attitudinal mediators, such as social (group) identification or need for affiliation, that researchers could explore in the crosscultural context.

Lastly, what comprises the work environment in a PE model could involve other work contexts in addition to meso-level organizational values and macro-level societal values. For example, the degree to which the work environment is 'political' could also make a difference in members' perception towards building relationships with their supervisors (Ferris et al., 2019). In a highly political work environment, where the relationship with one's supervisor is crucially important and instrumental in the employee's promotion and rewards, one's values orientations could be severely suppressed and the impact of values might even be completely negated (Gelfand et al., 2008).

\subsubsection{Future research directions}

Researchers could consider developing future LMX studies using values as predictors. First, the extant LMX literature could benefit from identifying how individual values have impact on the LMX relationship repair process. As reported by Ren and Gray (2009), the relationship repair process, in an intracultural dyad, has a bearing on individuals' values. They proposed that individualists as opposed to collectivists, would likely acknowledge the relationship violation more directly, use explicit language and emotions in their efforts to repair the resulting relationship conflict, and allow direct and overt acceptance of restorative actions. Our findings provide initial evidence that members' individual-level of collectivism and individualism matters in LMX quality. Hence, it supports Ren and Gray's cultural-values approach in understanding the relationship repair process in an intracultural work setting. Extrapolating this approach to the increasingly common intercultural work and team settings, we believe that members' values, specifically collectivism and individualism, could remain a promising predictor in understanding dyadic relationships.

Second, LMX is a dyadic process. As we found, members' values matter; thus, leaders' values likely matter, too. We are not aware of any scholarly attention that has been given to how leaders' values impact the LMX processes, while it is well acknowledged that leader-member values congruence is positively associated with LMX development and quality (Ashkanasy and O'Connor, 1997). Leaders' values could be a strong predictor of LMX outcomes, as the leader, rather than the member, is the more powerful party on whom the member has dependency. This suggests a research opportunity. Another possible, albeit more resource-demanding research opportunity related to the LMX dyadic process, would be to collect data from a wider variety of countries and from both leaders and members. As such, researchers could create a measure of congruence and assess the predictability of value congruence or other types of congruence cross-culturally.

In addition to future research opportunities emerging from the study limitations, there are a plethora of other LMX-related research opportunities because, as previously noted, the international LMX literature is still in its infancy. First, the extant LMX research is centered on six follower outcomes - organizational commitment, performance, turnover intentions, job satisfaction, citizenship behaviors, and justice perceptions (Nahrgang and Seo, 2015; Pellegrini, 2015). While these are important outcomes, research on other follower outcomes, such as innovative behavior, risk taking behavior, and corporate entrepreneurship, as well as group outcomes, such as team performance and cohesiveness, would help develop the foundation of the LMX literature, especially in the international context. Second, the extant international LMX studies used samples primarily from a few countries (China, Japan, India, Turkey, the Netherlands, Malaysia and Taiwan). As relationship is so fundamental to organizational effectiveness, there is a need to extend LMX research to other countries and continents to obtain a deeper and broader understanding of LMX in other business contexts (Pellegrini, 2015; Rockstuhl et al., 2012). Third, the current LMX research might have omitted some emic dimensions of LMX development and dynamics, as relationships are developed through different interactions and carry different obligations across cultures (Chong et al., 2015). A qualitative research design has been proposed to help address this gap (Pellegrini, 2015). Empirical exploration is needed. Lastly, recent developments in single-country LMX research have extended to examine other related constructs, for example, coworker-exchange (CWX; Sherony and Green, 2002), leader-leader exchange relations (LLX; Lorinkova and Perry, 2017), relative LMX (RLMX; Henderson et al., 2008), LMX social comparison (LMXSC; Vidyarthi et al., 2010) and economic versus social leader-member exchange (ELMX vs SLMX; Kuvaas et al., 2012). With these, we provide a sampling of the possible LMX topics that researchers could pursue in the international context.

\section{Conclusion}

To our knowledge, we present the first cross-cultural study to extend the current LMX literature by simultaneously examining the influence of culture at the individual, organizational, and societal levels on LMX quality. We empirically show that LMX quality is directly influenced by antecedents at both the individual-level and the organizational-level. Specifically, individual values and organizational culture have a significant, direct impact on LMX quality. Our findings—no interaction effects—also indicate that these direct effects may possibly be global.

LMX is currently the foremost dyadic leadership theory providing practical implications for managers and leaders. However, in the international context, the dearth of LMX research endeavors equates to LMX being an extremely under-researched area resulting in a negligible literature-base. Given the importance of LMX to leadership research and given the growing importance of developing global leadership theory in our heterogeneous, 21st century business world, there is an urgent need to substantially develop the LMX literature, including its antecedents and consequences, in a global context. To that end, our study, as the first multi-group, multi-level 
investigation of LMX, provides a meaningful step towards deepening our cross-cultural understanding of LMX quality. Moreover, the specifics of our key finding — LMX quality is impacted by both the individual-level and the organizational-level-provides salient direction for those wishing to engage in future LMX research endeavors. To close, this study provides a justification and a foundation for doing more extensive cross-cultural empirical research on LMX quality.

\section{References}

Adler, N.J., Gundersen, A., 2007. International Dimensions of Organizational Behavior. Cengage Learning.

Anand, S., Hu, J., Liden, R.C., Vidyarthi, P.R., 2011. Leader-member exchange: Recent research findings and prospects for the future. In: The Sage Handbook of Leadership, pp. 311-325.

Ashkanasy, N.M., O'Connor, C., 1997. Value congruence in leader-member exchange. J. Soc. Psychol. 137 (5), $647-662$.

Atwater, L., Carmeli, A., 2009. Leader-member exchange, feelings of energy, and involvement in creative work. Leadersh. Q. 20 (3), $264-275$.

Balliet, D., Wu, J., De Dreu, C.K., 2014. Ingroup favoritism in cooperation: a meta-analysis. Psychol. Bull. 140 (6), 1556.

Bartunek, J.M., Moch, M.K., 1987. First-order, second-order, and third-order change and organization development interventions: a cognitive approach. J. Appl. Behav. Sci. 23 (4), 483-500.

Bauer, T.N., Erdogan, B., 2015. Leader-member exchange (LMX) theory: an introduction and overview. In: Bauer, T.N., Erdogan, B. (Eds.), The Oxford Handbook of Leader-Member Exchange. Oxford university press, pp. 3-8.

Bauer, T.N., Green, S.G., 1996. Development of leader-member exchange: a longitudinal test. Acad. Manag. J. 39 (6), $1538-1567$.

Bauer, T.N., Erdogan, B., Liden, R.C., Wayne, S.J., 2006. A longitudinal study of the moderating role of extraversion: leader-member exchange, performance, and turnover during new executive development. J. Appl. Psychol. 91 (2), 298.

Boer, D., Hanke, K., He, J., 2018. On detecting systematic measurement error in cross-cultural research: a review and critical reflection on equivalence and invariance tests. J. Cross-Cult. Psychol. 49 (5), 713-734.

Brewer, M.B., 1999. The psychology of prejudice: Ingroup love and outgroup hate? J. Soc. Issues 55 (3), $429-444$.

Brewer, M.B., Chen, Y.R., 2007. Where (who) are collectives in collectivism? Toward conceptual clarification of individualism and collectivism. Psychol. Rev. 114 (1), 133.

Brislin, R.W., 1986. Research instruments. In: Field Methods in Cross-Cultural Research. vol. 8. pp. 137-164.

Cable, D.M., Judge, T.A., 1996. Person-organization fit, job choice decisions, and organizational entry. Organ. Behav. Hum. Decis. Process. 67 (3), 294-311.

Cameron, K.S., Ettington, D.R., 1988. The conceptual foundations of organizational culture. In: Higher Education: Handbook of Theory and Research. vol. 4. pp. 429-447.

Cameron, K.S., Quinn, R.E., 1999. Diagnosing and Changing Organizational Culture: Based on the Competing Values Framework. John Wiley \& Sons.

Cheung, G.W., Rensvold, R.B., 2002. Evaluating goodness-of-fit indexes for testing measurement invariance. Struct. Equ. Model. 9 (2), $233-255$.

Chong, M.P., Peng, T.K., Fu, P.P., Richards, M., Muethel, M., Caldas, M.P., Shang, Y.F., 2015. Relational perspectives on leaders' influence behavior: the mediation of Western leader-member exchange and Chinese Guanxi. J. Cross-Cult. Psychol. 46 (1), 71-87.

Dansereau Jr., F., Graen, G., Haga, W.J., 1975. A vertical dyad linkage approach to leadership within formal organizations: a longitudinal investigation of the role making process. Organ. Behav. Hum. Perform. 13 (1), 46-78.

Dawis, R.V., Lofquist, L.H., 1984. A Psychological Theory of Work Adjustment: An Individual-Differences Model and its Applications. University of Minnesota Press.

Dickson, M.W., Den Hartog, D.N., Mitchelson, J.K., 2003. Research on leadership in a cross-cultural context: making progress, and raising new questions. Leadersh. Q. 14 (6), 729-768.

Dulebohn, J.H., Bommer, W.H., Liden, R.C., Brouer, R.L., Ferris, G.R., 2012. A meta-analysis of antecedents and consequences of leader-member exchange: integrating the past with an eye toward the future. J. Manag. 38 (6), 1715-1759.

Eisenberger, R., Karagonlar, G., Stinglhamber, F., Neves, P., Becker, T.E., Gonzalez-Morales, M.G., Steiger-Mueller, M., 2010. Leader-member exchange and affective organizational commitment: the contribution of supervisor's organizational embodiment. J. Appl. Psychol. 95 (6), 1085.

Erdogan, B., Bauer, T.N., 2014. Leader-member exchange (LMX) theory: the relational approach to leadership. In: The Oxford Handbook of Leadership and Organizations, pp. 407.

Erdogan, B., Enders, J., 2007. Support from the top: supervisors' perceived organizational support as a moderator of leader-member exchange to satisfaction and performance relationships. J. Appl. Psychol. 92 (2), 321.

Erdogan, B., Liden, R.C., 2002. Social exchanges in the workplace. Leadership 65-114.

Erdogan, B., Liden, R.C., 2006. Collectivism as a moderator of responses to organizational justice: implications for leader-member exchange and ingratiation. J. Organ. Behav. 27 (1), 1-17.

Erdogan, B., Liden, R.C., Kraimer, M.L., 2006. Justice and leader-member exchange: the moderating role of organizational culture. Acad. Manag. J. 49 (2), 395-406.

Ferris, G.R., Ellen III, B.P., McAllister, C.P., Maher, L.P., 2019. Reorganizing organizational politics research: a review of the literature and identification of future research directions. Annual Review of Organizational Psychology and Organizational Behavior 6, $299-323$.

Fu, P.P., Kennedy, J., Tata, J., Yukl, G., Bond, M.H., Peng, T.K., ... Boonstra, J.J., 2004. The impact of societal cultural values and individual social beliefs on the perceived effectiveness of managerial influence strategies: a meso approach. J. Int. Bus. Stud. 35 (4), $284-305$.

Gelfand, M.J., Nishii, L.H., Raver, J.L., 2006. On the nature and importance of cultural tightness-looseness. J. Appl. Psychol. 91 (6), 1225.

Gelfand, M.J., Leslie, L.M., Fehr, R., 2008. To prosper, organizational psychology should... adopt a global perspective. Journal of Organizational Behavior: The International Journal of Industrial, Occupational and Organizational Psychology and Behavior 29 (4), $493-517$.

Gerstner, C.R., Day, D.V., 1997. Meta-analytic review of leader-member exchange theory: correlates and construct issues. J. Appl. Psychol. 82 (6), 827.

Gouldner, A.W., 1960. The norm of reciprocity: a preliminary statement. Am. Sociol. Rev. 161-178.

Graen, G.B., Uhl-Bien, M., 1995. Relationship-based approach to leadership: development of leader-member exchange (LMX) theory of leadership over 25 years: applying a multi-level multi-domain perspective. Leadersh. Q. 6 (2), 219-247.

Hanges, P.L., 2004. Response bias correction procedure used in GLOBE. In: House, R.J., Hanges, P.J., Javidan, M., Dorfman, P.W., Gupta, V. (Eds.), Culture, Leadership and Organization: The GLOBE Study of 62 Societies. CA: Sage, Thousand Oaks, pp. 737-751.

Hanges, P.J., Aiken, J.R., Park, J., Su, J., 2016. Cross-cultural leadership: leading around the world. Curr. Opin. Psychol. 8, 64-69.

Harris, S.G., 1994. Organizational culture and individual sensemaking: a schema-based perspective. Organ. Sci. 5 (3), $309-321$.

Harris, K.J., Harris, R.B., Brouer, R.L., 2009. LMX and subordinate political skill: direct and interactive effects on turnover intentions and job satisfaction. J. Appl. Soc. Psychol. 39 (10), 2373-2395.

Henderson, D.J., Wayne, S.J., Shore, L.M., Bommer, W.H., Tetrick, L.E., 2008. Leader-member exchange, differentiation, and psychological contract fulfilment: a multilevel examination. J. Appl. Psychol. 93 (6), 1208.

Heskett, J.L., Kotter, J.P., 1992. Corporate culture and performance. Business Review 2 (5), 83-93.

Hofstede, G., 1980. Culture's Consequences: Comparing Values, Behaviors, Institutions and Organizations across Nations. Sage publications.

Homer, P.M., Kahle, L.R., 1988. A structural equation test of the value-attitude-behavior hierarchy. J. Pers. Soc. Psychol. 54 (4), 638.

House, R.J., Hanges, P.J., Javidan, M., Dorfman, P.W., Gupta, V., 2004. Culture, Leadership and Organizations: The GLOBE Study of 62 Societies. Sage Publications, Thousand Oaks, CA.

Hox, J.J., 2010. Multilevel Analysis: Techniques and Applications, 2nd ed. Routledge, New York.

Ilies, R., Nahrgang, J.D., Morgeson, F.P., 2007. Leader-member exchange and citizenship behaviors: a meta-analysis. J. Appl. Psychol. 92 (1), 269.

Inglehart, R., 1997. Modernization and Postmodernization: Cultural, Economic, and Political Change in 43 Societies. Princeton University Press, Princeton, NJ. 
Joseph, D.L., Newman, D.A., Sin, H.P., 2011. Leader-member exchange (LMX) measurement: evidence for consensus, construct breadth, and discriminant validity. In: Building Methodological Bridges. Emerald Group Publishing Limited, pp. 89-135.

Kagitçibaşi, Ç., 1995. Is psychology relevant to global human development issues? Experience from Turkey. Am. Psychol. 50 (4), 293.

Karam, C.M., Ralston, D.A., 2016. A failure before analysis: the soup to nuts of preparing for multicountry analyses. Cross Cultural \& Strategic Management 23 (4), 590-612.

Kluckhohn, F.R., Strodtbeck, F.L., 1961. Variations in Value Orientations. Row, Peterson, Evanston, III.

Kristof-Brown, A., Guay, R.P., 2011. Person-environment fit. In: APA Handbook of Industrial and Organizational Psychology, Vol 3: Maintaining, Expanding, and Contracting the Organization. American Psychological Association, pp. 3-50.

Kristof-Brown, A.L., Zimmerman, R.D., Johnson, E.C., 2005. Consequences of individuals' fit at work: a meta-analysis of person-job, person-organization, person-group, and person-supervisor fit. Pers. Psychol. 58 (2), 281-342.

Kuvaas, B., Buch, R., Dysvik, A., Haerem, T., 2012. Economic and social leader-member exchange relationships and follower performance. Leadersh. Q. 23 (5), $756-765$.

Kwan, V.S., Bond, M.H., Singelis, T.M., 1997. Pancultural explanations for life satisfaction: adding relationship harmony to self-esteem. J. Pers. Soc. Psychol. 73 (5), 1038.

LeBreton, J.M., Senter, J.L., 2008. Answers to 20 questions about interrater reliability and interrater agreement. Organ. Res. Methods 11 (4), $815-852$.

Lewin, K., 1936/2013. Principles of Topological Psychology. Read Books Ltd.

Liao, H., Liu, D., Loi, R., 2010. Looking at both sides of the social exchange coin: a social cognitive perspective on the joint effects of relationship quality and differentiation on creativity. Acad. Manag. J. 53 (5), 1090-1109.

Liden, R.C., Maslyn, J.M., 1998. Multidimensionality of leader-member exchange: an empirical assessment through scale development. J. Manag. 24 (1), 43-72.

Liden, R.C., Wayne, S.J., Stilwell, D., 1993. A longitudinal study on the early development of leader-member exchanges. J. Appl. Psychol. 78 (4), 662.

Liden, R.C., Sparrowe, R.T., Wayne, S.J., 1997. Leader-member exchange theory: the past and potential for the future. In: Research in Personnel and Human Resources Management. vol. 15. pp. 47-120.

Liden, R.C., Wayne, S.J., Sparrowe, R.T., 2000. An examination of the mediating role of psychological empowerment on the relations between the job, interpersonal relationships, and work outcomes. J. Appl. Psychol. 85 (3), 407.

Liden, R.C., Wu, J., Cao, A.X., Wayne, S.J., 2015. Leader-member exchange measurement. In: The Oxford Handbook of Leader-Member Exchange, pp. 29.

Lorinkova, N.M., Perry, S.J., 2017. When is empowerment effective? The role of leader-leader exchange in empowering leadership, cynicism, and time theft. J. Manag. 43 (5), 1631-1654.

Markus, H.R., Kitayama, S., 1991. Culture and the self: implications for cognition, emotion, and motivation. Psychol. Rev. 98 (2), 224.

Maslyn, J.M., Uhl-Bien, M., 2001. Leader-member exchange and its dimensions: effects of self-effort and other's effort on relationship quality. J. Appl. Psychol. 86 (4), 697.

Nahrgang, J.D., Seo, J.J., 2015. How and why high leader-member exchange (LMX) relationships develop: Examining the antecedents of LMX. In: The Oxford Handbook of Leader-Member Exchange, pp. 87-118.

Nahrgang, J.D., Morgeson, F.P., Ilies, R., 2009. The development of leader-member exchanges: exploring how personality and performance influence leader and member relationships over time. Organ. Behav. Hum. Decis. Process. 108 (2), 256-266.

Nunnally, J.C., Bernstein, C., 1994. Psychometric Theory. McGrawHill, New York.

O'Reilly, C.A., Chatman, J.A., 1996. Culture as social control: Corporations, cults, and commitment. In: Staw, B.M., Cummings, L.L. (Eds.), Research in Organizational Behavior: An Annual Series of Analytical Essays and Critical Reviews. vol. 18. Elsevier Science/JAI Press, pp. 157-200.

O'Reilly, C.A., Chatman, J., Caldwell, D.F., 1991. People and organizational culture: a profile comparison approach to assessing person-organization fit. Acad. Manag. J. 34 (3), 487-516.

Pellegrini, E.K., 2015. Relational leadership through the lens of international LMX research. In: The Oxford Handbook of Leader-Member Exchange. Oxford Library of Psychology, pp. 351.

Peterson, M.F., Arregle, J.L., Martin, X., 2012. Multilevel models in international business research. J. Int. Bus. Stud. 43 (5), $451-457$.

Podsakoff, P.M., MacKenzie, S.B., Lee, J.Y., Podsakoff, N.P., 2003. Common method biases in behavioral research: a critical review of the literature and recommended remedies. J. Appl. Psychol. 88 (5), 879.

Purcell, J., Kinnie, N., 2007. HRM and business performance. In: Boxall, P., Purcell, J., Wright, P. (Eds.), The Oxford Handbook of Human Resource Management. Oxford University Press, New York, pp. 533-551.

Ralston, D. A.. (December 4, 2017). The guiding-forces model: a step toward developing a longitudinal, multilevel model of individuals' work behavior. Retrieved from SSRN: https://ssrn.com/abstract $=3082578$ or doi: https://doi.org/10.2139/ssrn. 3082578 .

Ralston, D.A., Pearson, A., 2010. The cross-cultural evolution of the subordinate influence ethics measure. J. Bus. Ethics 96 (1), $149-168$.

Ralston, D.A., Terpstra-Tong, J., Terpstra, R.H., Wang, X., Egri, C., 2006. Today's state-owned enterprises of China: are they dying dinosaurs or dynamic dynamos? Strateg. Manag. J. 27 (9), 825-843.

Ralston, D.A., Egri, C.P., Reynaud, E., Srinivasan, N., Furrer, O., Brock, D., Potocan, V., 2011. A twenty-first century assessment of values across the global workforce. J. Bus. Ethics 104 (1), 1-31.

Ralston, D.A., Egri, C.P., Furrer, O., Kuo, M.H., Li, Y., Wangenheim, F., ... Fu, P.P., 2014. Societal-level versus individual-level predictions of ethical behavior: a 48society study of collectivism and individualism. J. Bus. Ethics 122 (2), 283-306.

Ralston, D.A., Russell, C.J., Egri, C.P., 2018. Business values dimensions: a cross-culturally developed measure of workforce values. Int. Bus. Rev. 27, 1189-1199.

Raudenbush, S.W., Bryk, A.S., 2002. Hierarchical Linear Models: Applications and Data Analysis Methods. vol. 1 Sage.

Ren, H., Gray, B., 2009. Repairing relationship conflict: how violation types and culture influence the effectiveness of restoration rituals. Acad. Manag. Rev. 34 (1), 105-126.

Rockstuhl, T., Dulebohn, J.H., Ang, S., Shore, L.M., 2012. Leader-member exchange (LMX) and culture: a meta-analysis of correlates of LMX across 23 countries. J. Appl. Psychol. 97 (6), 1097.

Rokeach, M., 1973. The Nature of Human Values. Free press.

Ronen, S., Shenkar, O., 2013. Mapping world cultures: cluster formation, sources and implications. J. Int. Bus. Stud. 44 (9), $867-897$.

Scandura, T.A., 1999. Rethinking leader-member exchange: an organizational justice perspective. Leadersh. Q. 10 (1), $25-40$.

Scandura, T.A., Graen, G.B., 1984. Moderating effects of initial leader-member exchange status on the effects of a leadership intervention. J. Appl. Psychol. 69 (3), 428.

Schaubroeck, J., Lam, S.S., 2002. How similarity to peers and supervisor influences organizational advancement in different cultures. Acad. Manag. J. 45 (6), 1120-1136.

Schein, E.H., 2010. Organizational Culture and Leadership. vol. 2 John Wiley \& Sons.

Schriesheim, C.A., Cogliser, C.C., 2009. Construct validation in leadership research: explication and illustration. Leadersh. Q. 20 (5), $725-736$.

Schriesheim, C.A., Wu, J.B., Cooper, C.D., 2011. A two-study investigation of item wording effects on leader-follower convergence in descriptions of the leader-member exchange (LMX) relationship. Leadersh. Q. 22 (5), 881-892.

Schwartz, S.H., 1992. Universals in the content and structure of values: Theoretical advances and empirical tests in 20 countries. In: Advances in Experimental Social Psychology. vol. 25. Academic Press, pp. 1-65.

Schwartz, S.H., 1994. Beyond individualism/collectivism: new cultural dimensions of values. In: Kim, U., Triandis, H.C., Kagitcibasi, C., Choi, S.C., Yoon, G. (Eds.), Individualism, Collectivism: Theory, Applications, and Methods. Sage, Newbury Park, CA, pp. 85-119.

Schwartz, S.H., 2006. A theory of cultural value orientations: explication and applications. Comp. Sociol. 5 (2-3), 137-182.

Selvarajan, T.T., Singh, B., Solansky, S., 2018. Performance appraisal fairness, leader member exchange and motivation to improve performance: a study of US and Mexican employees. J. Bus. Res. 85, 142-154. 
Sherony, K.M., Green, S.G., 2002. Coworker exchange: relationships between coworkers, leader-member exchange, and work attitudes. J. Appl. Psychol. 87 (3), 542. Sørensen, J.B., 2002. The strength of corporate culture and the reliability of firm performance. Adm. Sci. Q. 47 (1), $70-91$.

Taras, V., Kirkman, B.L., Steel, P., 2010. Examining the impact of culture's consequences: a three-decade, multilevel, meta-analytic review of Hofstede's cultural value dimensions. J. Appl. Psychol. 95 (3), 405.

Taras, V., Steel, P., Kirkman, B., 2016. Does country equate with culture? Beyond geography in the search for cultural boundaries. Manag. Int. Rev. 56, 455-487.

Tett, R.P., Burnett, D.D., 2003. A personality trait-based interactionist model of job performance. J. Appl. Psychol. 88 (3), 500.

Tett, R.P., Guterman, H.A., 2000. Situation trait relevance, trait expression, and cross-situational consistency: testing a principle of trait activation. J. Res. Pers. 34 (4), 397-423.

Treviño, L.J., Egri, C.P., Ralston, D.A., Naoumova, I., Li, Y., Darder, F.L., ... Furrer, O., 2020. A cross-cultural examination of person-organization fit: is PO fit congruent with or contingent on societal values? Manag. Int. Rev. 1-28. https://doi.org/10.1007/s11575-020-00411-0.

Triandis, H.C., 1995. Individualism and Collectivism. Routledge.

Triandis, H.C., 2001. Individualism-collectivism and personality. J. Pers. 69 (6), 907-924.

Triandis, H.C., Singelis, T.M., 1998. Training to recognize individual differences in collectivism and individualism within culture. Int. J. Intercult. Relat. 22 (1), 35-47.

Triandis, H., Bontempo, R., Bond, M., Leung, K., Brenes, A., Georgas, J., Hui, C., Marin, G., Setiadi, B., Sinha, J., Verma, J., Spangenberg, J., Touzard, H., de Montmollin, G., 1986. The measurement of the etic aspects of individualism and collectivism across cultures. Aust. J. Psychol. 38, $257-267$.

Trompenaars, F., 1994. Riding the Waves of Culture: Understanding Diversity in Global Business. Irwin, Burr Ridge, IL.

Tung, R.L., 2008. The cross-cultural research imperative: the need to balance cross-national and intra-national diversity. J. Int. Bus. Stud. 39 (1), 41-46.

Uhl-Bien, M., Maslyn, J.M., 2003. Reciprocity in manager-subordinate relationships: components, configurations, and outcomes. J. Manag. 29 (4), 511-532.

Uhl-Bien, M., Graen, G.B., Scandura, T.A., 2000. Implications of leader-member exchange (LMX) for strategic human resource management systems: relationships as social capital for competitive advantage. In: Research in Personnel and Human Resources Management. vol. 18. pp. 137-186.

Van Vianen, A.E., 2000. Person-organization fit: the match between new comers' and recruiters' preferences for organizational cultures. Pers. Psychol. 53 (1), 113-149.

Vidyarthi, P.R., Liden, R.C., Anand, S., Erdogan, B., Ghosh, S., 2010. Where do I stand? Examining the effects of leader-member exchange social comparison on employee work behaviors. J. Appl. Psychol. 95 (5), 849.

Vora, d., Martin, L., Fitzsimmons, S.R., et al., 2018. Multiculturalism within individuals: a review, critique and agenda for future research. J. Int. Bus. Stud. https://doi. org/10.1057/s41267-018-0191-3.

Watts, L.L., Steele, L.M., Den Hartog, D.N., 2020. Uncertainty avoidance moderates the relationship between transformational leadership and innovation: a metaanalysis. J. Int. Bus. Stud. 51 (1), 138-145.

Wayne, S.J., Ferris, G.R., 1990. Influence tactics, affect, and exchange quality in supervisor-subordinate interactions: a laboratory experiment and field study. J. Appl. Psychol. 75 (5), 487.

World Values Survey Association, 2019. Data and documentation. Retrieved from. http://www.worldvaluessurvey.org/WVSContents.jsp.

Xu, E., Huang, X., Lam, C.K., Miao, Q., 2012. Abusive supervision and work behaviors: the mediating role of LMX. J. Organ. Behav. 33 (4), 531-543.

Yu, K.Y.T., 2013. A motivational model of person-environment fit: psychological motives as drivers of change. In: Kristof-Brown, A.L., Billsberry, J. (Eds.), Organizational Fit: Key Issues and New Directions. Wiley-Blackwell, pp. 21-49.

Zhang, Z., Waldman, D.A., Wang, Z., 2012. A multilevel investigation of leader-member exchange, informal leader emergence, and individual and team performance. Pers. Psychol. 65 (1), 49-78. 